\title{
Chemopreventive effect of fermented brown rice and rice bran on 4-nitroquinoline 1-oxide-induced oral carcinogenesis in rats
}

\author{
NGUYEN KHANH LONG, HIROKI MAKITA, TOMOMI YAMASHITA, MAKOTO TOIDA, \\ KEIZO KATO, DAIJIRO HATAKEYAMA and TOSHIYUKI SHIBATA \\ Department of Oral and Maxillofacial Sciences, Gifu University, \\ Graduate School of Medicine, 1-1 Yanagido, Gifu 501-1194, Japan
}

Received August 17, 2006; Accepted October 26, 2006

\begin{abstract}
The preventive effects of the dietary administration of brown rice and rice bran fermented with Aspergillus oryzae (FBRA) on oral carcinogenesis induced by 4-nitroquinoline 1-oxide (4-NQO) were investigated in male F344 rats. At 7 weeks of age, the animals were given 20 ppm 4-NQO in their drinking water for 8 weeks to induce tongue neoplasms. Groups of rats were fed diets containing 5 or $10 \%$ FBRA during the initiation or postinitiation phases of the 4-NQO-induced oral carcinogenesis. The other groups consisted of rats fed $10 \%$ FBRA or untreated rats. At the termination of the study (week 32), the incidences, multiplicities of tongue lesions (preneoplasms and neoplasms) and the cell proliferation activity estimated by the 5-bromodeoxyuridine (BrdU)-labeling index were compared among the groups. Feeding of 5\% FBRA during the initiation phase significantly decreased the incidence (68.2 vs $36.8 \% ; \mathrm{p}<0.05)$ and multiplicity $(1.05 \pm 0.84$ vs $0.37 \pm 0.50 ; \mathrm{p}<0.005)$ of the tongue carcinoma. When feeding of $10 \%$ FBRA occurred after the 4-NQO exposure, the multiplicity of tongue carcinoma was also reduced $(1.05 \pm 0.84$ vs $0.52 \pm 0.60 ; \mathrm{p}<0.05)$. In addition, the dietary administration of FBRA at both doses significantly decreased the BrdU-labeling index in the oral squamous epithelium $(\mathrm{p}<0.05)$. Although a dose-dependent response was not observed, FBRA is effective in suppressing the development of 4-NQO-induced oral carcinogenesis by its concurrent exposure to the carcinogen. The inhibitory effect could be related to the suppression of the hyperproliferation of cells in the tongue epithelium and the radical scavenging activity of FBRA.
\end{abstract}

Correspondence to: Dr Hiroki Makita, Department of Oral and Maxillofacial Sciences, Gifu University, Graduate School of Medicine, 1-1 Yanagido, Gifu 501-1194, Japan

E-mail:makitah@gifu-u.ac.jp

Abbreviations: 4-NQO, 4-nitroquinoline 1-oxide; FBRA, brown rice fermented with Aspergillus oryzae; BrdU, 5-bromodeoxyuridine

Key words: fermented brown rice, rice bran, chemoprevention, rat, oral carcinogenesis

\section{Introduction}

Cancer of the oral cavity, mostly squamous cell carcinoma, is one of the most common neoplasms in the world $(1,2)$. Worldwide, an estimated 390,000 new cases of oral cancer are diagnosed each year (3). Oral cancer incidence varies markedly around the world with the highest rates reported in developing countries, particularly in Southern Asia (India, Srilanka, Vietnam, and the Philippines), China and parts of Brazil (4). Unfortunately, the progress of therapeutic approaches for this malignancy has not yet been sufficient to control the carcinogenic process. Despite advances in surgical procedures, radiation, and chemotherapy, the five-year survival rate for oral cancer has not improved significantly over the past several decades and it remains at about 50 to $55 \%$ (5). Furthermore, neoplasms in the head and neck, including the oral cavity, possess certain biological properties that are multistage and multifocal carcinogenesis. Patients with oral cancer have an increased risk of developing second primary lesions of the upper aerodigestive tract within a few years after primary treatment $(4,6,7)$. Hence, it is important to discover a novel strategy to prevent and/or manage oral lesions early and effectively. One such promising approach is chemoprevention, which is a preventive strategy carried out by the dietary administration of certain natural or synthetic compounds $(1,4)$.

Epidemiological and preclinical studies have clearly shown that nutrition plays an important role in reducing the risk of oral cancer (8). One of the suitable animal models for studying the chemoprevention of oral cancer is 4-nitroquinoline 1-oxide (4-NQO)-induced rat oral carcinogenesis $(9,10)$. 4-NQO, a water-soluble quinoline derivative, produces a spectrum of preneoplastic and neoplastic lesions in the oral cavity, especially on the tongue of rats following the 4-NQO application in drinking water or topically to the oral mucosa. Oral lesions induced by 4-NQO are morphologically and histopathologically comparable to human lesions (10-12). Using 4-NQO-induced rat oral carcinogenesis models, naturally-occurring and related synthetic agents and other anti-oxidant/free radical scavengers derived from food have been reported to inhibit oral carcinogenesis (13-31).

Rice is one of the major cereal foods in staple diets worldwide, especially in Asian countries. It has been reported that rice components, especially rice germs, play a key role 


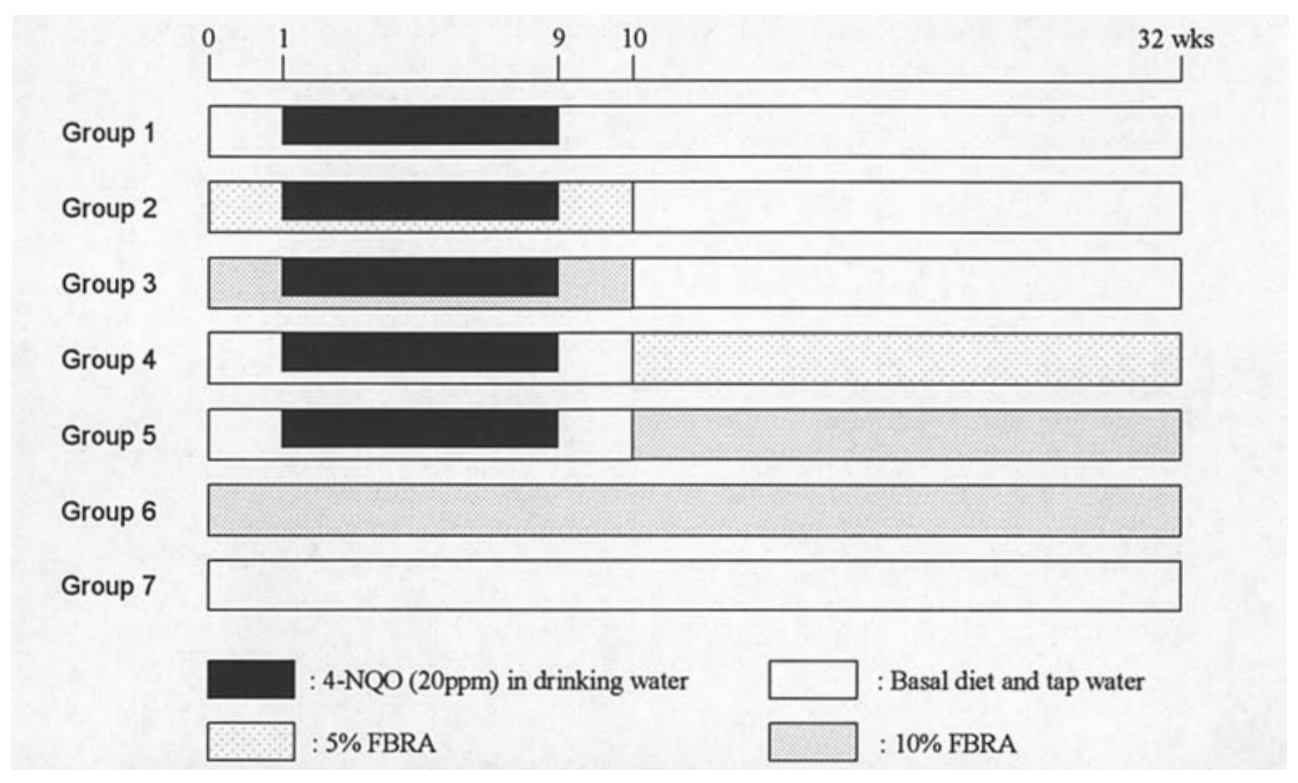

Figure 1. Experimental protocol.

in the prevention of cancer (32-35). Rice seeds and germs contain fiber and several kinds of anti-oxidants, such as ferulic acid (36), phytic acid, tocopherol and oryzarol (32), and related compounds, which are known for their anticancer properties (35). Among them, ferulic acid has been reported to prevent chemically-induced oral cancer in animal models (24). The chemoprevention of cancer by rice-based and other types of cereal grains as a food supplement is therefore a promising strategy without side effects and toxicity. Brown rice fermented with Aspergillus oryzae (FBRA) is a processed food prepared by fermenting brown rice and rice bran with Aspergillus oryzae. In previous studies, the dietary administration of FBRA had inhibitory effects on the carcinogenesis of the colon, liver, bladder and esophagus in rodents (32-35).

In the present study, we investigate the potential anticancer properties of FBRA against oral carcinogenesis induced by 4-NQO in male F344 rats. The effects of FBRA on the cell proliferation of the tongue squamous epithelium were also examined by measuring the 5-bromodeoxyuridine (BrdU)labeling index.

\section{Materials and methods}

Animals, diets, chemicals and carcinogens. Male F344 rats, 4 weeks old, were purchased from Japan SLC, Inc. (Shizuoka, Japan). The rats were housed in a holding room under the controlled conditions of a 12-h light/dark cycle, $23 \pm 2{ }^{\circ} \mathrm{C}$ temperature, and $50 \pm 10 \%$ humidity. After 2 weeks of quarantine, the rats were randomized into experimental and control groups. They were housed three or four to a wire cage. Food and water were available ad libitum. Powder CE-2 (CLEA Japan, Inc., Tokyo, Japan) was used as the basal diet during the experiment. FBRA was supplied by Genmai Koso Co., Ltd. (Sapporo, Japan). Briefly, the manufacturing process of FBRA is as follows: The fermentation base was made by steaming the brown rice and rice bran. Aspergillus oryzae was then seeded to the fermentation base and the fermentation process was continued for 18-24 h. Subsequently, a second fermentation was continued for an additional 12-24 h for aging purposes. The fermented product was then dried and powdered. The experimental diets were prepared by mixing 5 and $10 \%$ FBRA with the CE-2 diet and stored in a cold room.

Experimental procedures. A total of 129 rats were randomly divided into 7 groups as shown in Fig. 1. At 7 weeks of age, the rats in groups $1-5$ were given 20 ppm 4-NQO in their drinking water for 8 weeks to induce tongue neoplasms. Starting at 6 weeks of age, groups 2 and 3 were fed the diets containing 5 and 10\% FBRA for 10 weeks, respectively, and then switched to the basal diet, continuing for 22 weeks. The rats in groups 4 and 5 were fed the diets containing 5 and $10 \%$ FBRA, respectively, starting 1 week after the cessation of the 4-NQO treatment and continuing for 22 weeks. The rats in group 6 were fed on 10\% FBRA throughout the experimental period and the animals in group 7 received the basal diet and tap water during the study period and served as the untreated control. All rats were carefully inspected daily, and the consumption of drinking water containing 4-NQO or the experimental diets mixed with the test compound was recorded to estimate the intake of the chemicals. The experiment was terminated at 32 weeks, and all the animals were sacrificed. At necropsy, all the organs including the oral cavity were carefully inspected to find preneoplastic and neoplastic lesions. The rat tongues were cut into halves longitudinally. For the histological examination, the tissues and gross lesions were fixed in $10 \%$ buffered formalin embedded in paraffin blocks, and the sections were stained with H\&E. The epithelial lesions (hyperplasia, dysplasia and neoplasia) in the oral cavity were diagnosed according to the criteria described by Kramer et al (37).

Determination of the proliferative activity of tongue epithelium by BrdU-labeling index. To assess the proliferative activity of the tongue squamous epithelium, the BrdU-labeling indices were quantified. For the measurement of BrdU-incorporated nuclei, the animals were given an intraperitoneal injection of 
Table I. Body, liver and relative liver weight among the rats in each group.

\begin{tabular}{llcccc}
\hline Group & \multicolumn{1}{c}{ Treatment } & $\begin{array}{c}\text { No. of rats } \\
\text { examined }\end{array}$ & $\begin{array}{c}\text { Body } \\
\text { weight }(\mathrm{g})\end{array}$ & $\begin{array}{c}\text { Liver } \\
\text { weight }(\mathrm{g})\end{array}$ & $\begin{array}{c}\text { Relative liver weight } \\
(\mathrm{g} / 100 \mathrm{~g} \text { body weight })\end{array}$ \\
\hline 1 & 4-NQO alone & 22 & $349 \pm 63^{\mathrm{a}, \mathrm{c}}$ & $10.9 \pm 1.3^{\mathrm{b}}$ & $3.05 \pm 0.23^{\mathrm{d}}$ \\
2 & 4-NQO + 5\% FBRA & 19 & $359 \pm 50^{\mathrm{c}}$ & $11.4 \pm 2.1^{\mathrm{d}}$ & $3.17 \pm 0.39$ \\
3 & 4-NQO + 10\% FBRA & 20 & $342 \pm 59^{\mathrm{b}}$ & $11.0 \pm 2.9^{\mathrm{d}}$ & $3.17 \pm 0.48$ \\
4 & 4-NQO - >5\% FBRA & 21 & $362 \pm 46^{\mathrm{c}}$ & $12.2 \pm 3.0^{\mathrm{d}}$ & $3.33 \pm 0.59$ \\
5 & 4-NQO - >10\% FBRA & 21 & $366 \pm 22^{\mathrm{b}}$ & $10.7 \pm 1.2^{\mathrm{b}}$ & $2.92 \pm 0.24^{\mathrm{c}}$ \\
6 & 10\% FBRA & 12 & $377 \pm 15^{\mathrm{b}}$ & $11.3 \pm 1.2^{\mathrm{c}}$ & $2.98 \pm 0.30$ \\
7 & No treatment & 14 & $403 \pm 16$ & $12.9 \pm 1.2$ & $3.19 \pm 0.22$ \\
\hline
\end{tabular}

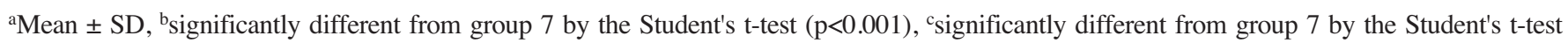
$(\mathrm{p}<0.01),{ }^{\mathrm{d}}$ significantly different from group 7 by the Student's t-test $(\mathrm{p}<0.05)$.

$50 \mathrm{mg} / \mathrm{kg}$ body weight BrdU (Sigma Chemical Co., St Louis, MO, USA) $1 \mathrm{~h}$ prior to sacrificing. One half of the tongue was used and processed to make serial sections after being embedding in paraffin. One section was used for histopathology, and the other for the immunohistochemical detection of the BrdU incorporation using an immunohistochemical analysis kit (Dako Japan, Kyoto, Japan). The labeling indices were calculated by counting the BrdUpositive nuclei in at least 800 cells at four different fields of the normal or non-lesional tongue epithelium of each rat under x400 magnification.

Statistical analysis. Statistical analysis on the incidence of the lesions was performed using Yates' corrected Chi-square test or Fisher's exact probability test, and the data from the measurements of the body and liver weights, multiplicity of tumors, and the BrdU-labeling index were compared by the Student's t-test. The results were considered statistically significant at $\mathrm{p}$-value $\leq 0.05$.

\section{Results}

General observations. Animals in groups 1-5 tolerated the oral administration of 4-NQO and/or FBRA well. Food intake for the test chemical groups was 16.7-18.5 g/day/rat. The final mean body and liver weights of the rats that received 4-NQO treatment (groups 1-5) were significantly reduced in comparison to the control group (group 7) as shown in Table I. This could be caused by the fact that some of the rats' body weights were reduced due to the tumor development. However, there was no significant difference in the relative liver weight among these groups. In this study, the dietary administration of FBRA caused no clinical signs or histological changes suggesting toxicity in any organ of the animals.

Incidence and multiplicity of tumors and preneoplastic lesions. In the present study, endophytic or exophytic tumors developed in the dorsal site of the tongues of the rats in groups 1-5. The tongue tumors were histopathologically squamous cell papillomas and well-differentiated squamous cell carcinomas. Only one rat in group 1 had a local invasion in the left buccal region. The animals in groups 6 and 7 did not have any preneoplastic or neoplastic lesions. The incidence and multiplicity of tongue neoplasms (squamous cell papillomas and carcinomas) in each group are shown in Tables II and III, respectively. In group 1 (4-NQO alone), the incidence of tongue squamous cell carcinomas and squamous cell papillomas was $68.2 \%$ (15/22 rats) and $13.6 \%(3 / 22$ rats), respectively. In contrast, the administration of FBRA during the initiation and the postinitiation phases decreased the incidence and multiplicity of the tongue neoplasms. A significant inhibition of the incidence and multiplicity of squamous cell carcinoma $(\mathrm{p}<0.05)$ and total neoplasms $(\mathrm{p}<0.005)$ by feeding the rats 5\% FBRA during the initiation phase (group 2) was observed. Although the tumor incidences in groups 3-5 were not significantly different from those in group 1, the multiplicities of total neoplasms in groups 3 and $5(0.67 \pm 0.66$ and $0.70 \pm 0.47$, respectively) and squamous cell carcinoma in group $5(0.52 \pm 0.60)$ were also significantly less than those of group $1(\mathrm{p}<0.05)$. Dysplastic lesions with various degrees of atypia were also found in the tongues as shown in Table IV. Feeding the rats FBRA during the initiation and postinitiation phase decreased the development of severe dysplasia in groups 2-5, although there were no significant differences in the incidences and multiplicities of preneoplastic lesions (hyperplasia and dysplasia) among the rats fed FBRA and the control group.

BrdU-labeling index. The results of the morphometric analysis of the BrdU-labeling indices in the non-lesional tongue squamous epithelium are summarized in Table $\mathrm{V}$. The mean BrdU-labeling index for the tongue epithelium exposed to 4-NQO alone (group 1) was the highest among the groups and was significantly greater than that of the untreated control (group 7) $(\mathrm{p}<0.001)$. The dietary administration of FBRA at 5 and $10 \%$ during the initiation phase (groups 2 and 3) and at $10 \%$ during the postinitiation phase (group 5) significantly decreased the indices when compared with group $1(\mathrm{p}<0.005$, $<0.05$, and $<0.05$, respectively). The average BrdU-labeling indices in groups 6 and 7 were similar. 
Table II. The incidence of tongue preneoplasms and neoplasms among the rats in each group.

\begin{tabular}{|c|c|c|c|c|c|c|c|}
\hline \multirow[b]{2}{*}{ Group } & \multirow[b]{2}{*}{ Treatment } & \multirow[b]{2}{*}{$\begin{array}{l}\text { No. of rats } \\
\text { examined }\end{array}$} & \multirow[b]{2}{*}{$\begin{array}{c}\text { Hyperplasia } \\
(\%)\end{array}$} & \multirow[b]{2}{*}{$\begin{array}{c}\text { Dysplasia } \\
(\%)\end{array}$} & \multicolumn{3}{|c|}{ Rats with tongue tumors } \\
\hline & & & & & $\begin{array}{c}\text { Total } \\
(\%)\end{array}$ & $\begin{array}{l}\text { Squamous cell } \\
\text { papilloma }(\%)\end{array}$ & $\begin{array}{l}\text { Squamous cell } \\
\text { carcinoma }(\%)\end{array}$ \\
\hline 1 & 4-NQO alone & 22 & $22(100)$ & $22(100)$ & $16(72.7)$ & $3(13.6)$ & $15(68.2)$ \\
\hline 2 & $4-\mathrm{NQO}+5 \%$ FBRA & 19 & $19(100)$ & $19(100)$ & $8(42.1)^{\mathrm{a}}$ & $1 \quad(5.3)$ & $7(36.8)^{\mathrm{a}}$ \\
\hline 3 & 4-NQO + 10\% FBRA & 20 & $20(100)$ & $20(100)$ & $14(70.0)$ & $1(5.0)$ & $13(65.0)$ \\
\hline 4 & 4-NQO - >5\% FBRA & 21 & $21(100)$ & $21(100)$ & $13(61.9)$ & 1 (4.8) & $13(61.9)$ \\
\hline 5 & 4-NQO - >10\% FBRA & 21 & $21(100)$ & $20(95.2)$ & $12(57.1)$ & $3(14.3)$ & $10(47.6)$ \\
\hline 6 & $10 \%$ FBRA & 12 & 0 & 0 & 0 & 0 & 0 \\
\hline 7 & No treatment & 14 & 0 & 0 & 0 & 0 & 0 \\
\hline
\end{tabular}

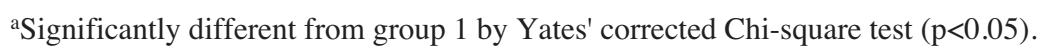

Table III. The multiplicity of tongue tumors among the rats in each group.

\begin{tabular}{llcccc}
\hline & & & \multicolumn{2}{c}{ Multiplicity of tumors } \\
\cline { 5 - 6 } Group & \multicolumn{1}{c}{ Treatment } & $\begin{array}{c}\text { No. of rats } \\
\text { examined }\end{array}$ & Total & $\begin{array}{c}\text { Squamous cell } \\
\text { papilloma }\end{array}$ & $\begin{array}{c}\text { Squamous cell } \\
\text { carcinoma }\end{array}$ \\
\hline 1 & 4-NQO alone & 22 & $1.23 \pm 1.02^{\mathrm{a}}$ & $0.18 \pm 0.51$ & $1.05 \pm 0.84$ \\
2 & $4-\mathrm{NQO}+5 \%$ FBRA & 19 & $0.42 \pm 0.51^{\mathrm{b}}$ & $0.05 \pm 0.23$ & $0.37 \pm 0.50^{\mathrm{b}}$ \\
3 & 4-NQO + 10\% FBRA & 20 & $0.70 \pm 0.47^{\mathrm{c}}$ & $0.05 \pm 0.22$ & $0.65 \pm 0.49$ \\
4 & $4-\mathrm{NQO}->5 \%$ FBRA & 21 & $0.81 \pm 0.75$ & $0.05 \pm 0.22$ & $0.76 \pm 0.70$ \\
5 & 4-NQO - >10\% FBRA & 21 & $0.67 \pm 0.66^{\mathrm{c}}$ & $0.14 \pm 0.36$ & $0.52 \pm 0.60^{\mathrm{c}}$ \\
6 & $10 \%$ FBRA & 12 & 0 & 0 & 0 \\
7 & No treatment & 14 & 0 & 0 & 0 \\
\hline
\end{tabular}

${ }^{\mathrm{a}}$ Mean $\pm \mathrm{SD}$, ${ }^{\mathrm{b}}$ significantly different from group 1 by the Student's t-test $(\mathrm{p}<0.005)$, ${ }^{\mathrm{c}}$ significantly different from group 1 by the Student's t-test $(\mathrm{p}<0.05)$.

Table IV. The incidence of various types of tongue dysplasia among the rats in each group.

\begin{tabular}{|c|c|c|c|c|c|c|}
\hline \multirow[b]{2}{*}{ Group } & \multirow[b]{2}{*}{ Treatment } & \multirow[b]{2}{*}{$\begin{array}{l}\text { No. of rats } \\
\text { examined }\end{array}$} & \multicolumn{4}{|c|}{ Dysplasia } \\
\hline & & & Total $(\%)$ & Mild (\%) & Moderate (\%) & Severe $(\%)$ \\
\hline 1 & 4-NQO alone & 22 & $22(100)$ & $22(100)$ & $21(95.5)$ & $19(86.4)$ \\
\hline 2 & $4-\mathrm{NQO}+5 \%$ FBRA & 19 & $19(100)$ & $19(100)$ & $17(89.5)$ & $13(68.4)$ \\
\hline 3 & 4-NQO + 10\% FBRA & 20 & $20(100)$ & $20(100)$ & $19(95.0)$ & $15(75.0)$ \\
\hline 4 & 4-NQO - >5\% FBRA & 21 & $21(100)$ & $21(100)$ & $20(95.2)$ & $17(81.0)$ \\
\hline 5 & 4-NQO - >10\% FBRA & 21 & $20(95.2)$ & $20(95.2)$ & $20(95.2)$ & $17(81.0)$ \\
\hline 6 & $10 \%$ FBRA & 12 & 0 & 0 & 0 & 0 \\
\hline 7 & No treatment & 14 & 0 & 0 & 0 & 0 \\
\hline
\end{tabular}

\section{Discussion}

In the present study, the dietary administration of FBRA during the initiation or postinitiation phases effectively inhibited 4-NQO-induced oral carcinogenesis without any toxicity and pathological alteration of other organs in rats. Our results clearly indicate that the dietary administration of 5\% FBRA during the initiation phase significantly suppresses 
Table V. The BrdU-labeling index of the non-lesional area of the tongue squamous epithelium.

\begin{tabular}{llcc}
\hline Group & \multicolumn{1}{c}{ Treatment } & $\begin{array}{c}\text { No. of rats } \\
\text { examined }\end{array}$ & $\begin{array}{c}\text { BrdU labelling } \\
\text { index (\%) }\end{array}$ \\
\hline 1 & 4-NQO alone & 8 & $9.77 \pm 1.54^{\mathrm{a}, \mathrm{b}}$ \\
2 & 4-NQO + 5\% FBRA & 8 & $7.59 \pm 0.94^{\mathrm{c}}$ \\
3 & 4-NQO + 10\% FBRA & 8 & $7.89 \pm 1.08^{\mathrm{d}}$ \\
4 & 4-NQO - >5\% FBRA & 8 & $8.16 \pm 2.01$ \\
5 & 4-NQO - >10\% FBRA & 8 & $7.96 \pm 1.68^{\mathrm{d}}$ \\
6 & 10\% FBRA & 8 & $7.43 \pm 1.59$ \\
7 & No treatment & 8 & $7.02 \pm 1.23$ \\
\hline
\end{tabular}

${ }^{\mathrm{a}}$ Mean $\pm \mathrm{SD}$, ${ }^{\mathrm{b}}$ significantly different from group 7 by the Student's $\mathrm{t}$-test $(\mathrm{p}<0.001)$, 'significantly different from group 1 by the Student's t-test $(\mathrm{p}<0.005)$, ${ }^{\mathrm{d}}$ significantly different from group 1 by the Student's t-test $(\mathrm{p}<0.05)$.

the formation and growth of squamous cell carcinoma induced by $4-\mathrm{NQO}$. Feeding the rats $10 \%$ FBRA during the postinitiation phase did not significantly affect the incidence of the tongue tumors, although the treatment significantly decreased the multiplicity of the squamous cell carcinoma. This tumor-inhibitory activity is consistent with previous studies showing that FBRA inhibits the carcinogenesis of the colon, liver, esophagus and urinary bladder in rodents (32-35). The inhibition of FBRA in this study is not in a dose-dependent manner. In contrast to the dose-dependent preventive effect of FBRA on N-nitrosomethylbenzylamine (NMBA)-induced esophageal tumorigenesis in rats or urinary bladder carcinogenesis induced by N-butyl-N-(4-hydroxybutyl)-nitrosamine $(\mathrm{OH}-\mathrm{BBN})$ in mice mostly in the postinitiation phase (32-33), the low dose $(5 \%)$ of FBRA was more effective in inhibiting tongue carcinogenesis induced by 4-NQO during the initiation phase. The exact reasons for this difference are not known, although it could be due to the variations of the experimental conditions, such as the different carcinogens and target organs used. However, our data suggest that 5\% FBRA is possibly the optimal dose in suppressing tongue carcinogenesis in the initiation phase. Additional investigations regarding tissue distribution or the organ-specific effects of FBRA are needed to clarify this point.

Cell proliferation plays an important role in the initiation step of carcinogenesis. The control of cell proliferation in the target organs is regarded as a fundamental mode of action of chemopreventive agents $(10,38)$. In this study, the dietary administration of FBRA during the initiation and postinitiation phases decreased the BrdU-labeling indices when compared with the carcinogen alone. Therefore, FBRA significantly inhibited the cell proliferation activity in the tongue mucosa induced by 4-NQO, suggesting that dietary FBRA could suppress the high proliferative activity of cells initiated with a carcinogen and inhibit carcinogenesis. These results are comparable to previous experiments, demonstrating the preventive effects of several natural anti-oxidants and certain synthetic compounds against oral cancer $(13-31,39)$. To date, the mechanisms involved in the inhibition of the initiation or postinitiation events of oral carcinogenesis by FBRA are not clear. However, ferulic acid, one of the FBRA constituents, and other polyphenolic compounds such as caffeic acid, ellagic acid, and chlorogenic acid have been reported to inhibit the 4-NQO-induced tongue carcinogenesis during the initiation phase by suppressing the hyperproliferation of cells in the tongue epithelium $(15,38)$. Other chemopreventive agents such as beta-carotene, hesperidin, and curcumin also exert similar effects $(16,23,38)$. Thus, one of the mechanisms by which FBRA exerts its chemopreventive activity could be related to the suppression of cell proliferation in the target tissue.

In addition, 4-NQO exerts potent intracellular oxidative stress and its metabolic product binds to DNA predominantly at guanine residues. It generates reactive oxygen species (ROS) such as superoxide radical or hydrogen peroxide. 4-NQO can undergo redox cycling and produce ROS, which contribute to tumor promotion (10). Traditional fermented foods in Asian countries are usually prepared by the solid fermentation of steamed soybean, rice, barley, wheat and mixtures of wheat flour, with microorganisms such as Aspergillus sp., Rhizopus sp., and Bacillus natto. Some of these microorganisms have also been reported to produce physiological substances associated with anti-oxidant and antibacterial activity (40). FBRA is a processed food prepared by fermenting brown rice and rice bran with Aspergillus oryzae. It is already known that FBRA acts as a potent free radical scavenger (32), but the details are not well elucidated. Japanese traditional soybean products fermented with Aspergillus oryzae such as soybean paste (miso) and soy sauces (shoyu) have been found to contain several anti-oxidative isoflavones such as 6-hydroxydaidzein (6-OHD), 8-hydroxydaidzein (8-OHD) and 8-hydroxygenistein, which make them more stable against lipid peroxidation than unfermented soybeans (41). These 8-hydroxyisoflavones have been reported to possess greater 1,1-diphenyl-2-picrylhydrazyl (DPPH) radicalscavenging activity and antiproliferative activity than the corresponding isoflavone analogs (42). In addition, these 8hydroxyisoflavones and 6-OHD showed high antimutagenic activity. Several epidemiological and preclinical studies have suggested the preventive effects of such fermented soybean products (41-46). Recently, the extracts of fermented soybean Koji with its abundant hydrolytic enzyme and improved anti-oxidative activity have been found to enhance the antimutagenic effect on the mutagenesis of 4-NQO in in vitro tests (40). Moreover, Shimoji et al reported that dihydroferulic acid and dihydrosinapic acid were isolated from Kurosu (unpolished rice vinegar) as the major constituents responsible for its radical scavenging activity (47). These acids are produced in Kurosu through the process of the fermentation from ferulic acid and sinapic acid, respectively. It is possible that FBRA also exerts similar mechanistic principles to the fermented soybeans or Kurosu. In addition, phenolic acids contained in plant materials such as rice, green tea, and coffee beans possess a variety of biological functions including antioxidative activities. Their chemopreventive action on carcinogenesis is the suppression of metabolic activation and enhancement of detoxification that could also be related to 
the blocking effect on mutagenesis and carcinogenesis (36). Further research is required to better understand the mechanisms by which dietary FBRA inhibits oral carcinogenesis.

In summary, the dietary administration of FBRA inhibits carcinogenesis in the 4-NQO-induced oral carcinogenesis rat model. The dietary feeding of 5\% FBRA during the initiation phase significantly suppresses tumor development and cell proliferation in the tongue epithelium. Our data together with previous reports $(32-35)$ indicate that FBRA as a food supplement is a promising chemopreventive agent that possesses anticarcinogenic potency on the tumorigenesis of different organ sites (liver, colon, esophagus, urinary bladder, and oral cavity) possibly by the inhibition of cell proliferation and its anti-oxidant effects. Further investigations are necessary to clarify the mechanism regarding the inhibitory effects of FBRA on carcinogenesis.

\section{References}

1. Anne ST, Edward SK and Waun KH: Chemoprevention of Cancer. CA Cancer J Clin 54: 150-180, 2004.

2. Keith DH and Parkinson EK: Profiling early head and neck cancer. Nat Rev Cancer 5: 127-135, 2005.

3. Suzuki R, Kohno H, Suzui M, Yoshimi N, Tsuda H, Wakabayashi $\mathrm{K}$ and Tanaka T: An animal model for the rapid induction of tongue neoplasms in human c-Ha-ras protooncogene transgenic rats by 4-nitroquinoline 1-oxide: its potential use for preclinical chemoprevention studies. Carcinogenesis 27: 619-630, 2006.

4. Tanaka T: Chemoprevention of oral carcinogenesis. Oral Oncol, Eur J Cancer 31B: 3-15, 1995.

5. Brad WN and Terry AD: Oral cancer and precancerous lesions. CA Cancer J Clin 52: 195-215, 2002.

6. Van Oijen MG and Slootweg PJ: Oral field cancerization: carcinogen-induced independent events or micrometastatic deposits? Cancer Epidemiol Biomarkers Prev 9: 249-256, 2000.

7. Jesper R: Prognosis of oral pre-malignant lesions: significance of clinical, histopathological and molecular biological characteristics. Crit Rev Oral Biol Med 14: 47-62, 2003.

8. Enwonwu CO: Bionutrition and oral cancer in humans. Crit Rev Oral Biol Med 6: 5-17, 1995.

9. Tanaka T, Kojima T, Okumura A, Yoshimi N and Mori H: Alterations of the nucleolar organizer regions during 4nitroquinoline 1-oxide-induced tongue carcinogenesis in rats. Carcinogenesis 12: 329-333, 1991.

10. Deepak K and Milind MV: 4-Nitroquinoline-1-oxide induced experimental oral carcinogenesis. Oral Oncol 42: 655-667, 2006.

11. Yoshida K, Tanaka T, Hirose Y, Yamaguchi F, Kohno H, Toida M, et al: Dietary garcinol inhibits 4-nitroquinoline-1oxideinduced tongue carcinogenesis in rats. Cancer Lett 221: 29-39, 2005.

12. Makita H, Tanaka T, Fujitsuka H, Tatematsu N, Satoh K, Hara A and Mori $\mathrm{H}$ : Chemoprevention of 4-nitroquinoline 1-oxideinduced rat oral carcinogenesis by the dietary flavonoids chalcone, 2-hydroxychalcone, and quercetin. Cancer Res 56: 4904-4909, 1996.

13. Tanaka T, Kojima T, Morishita Y and Mori H: Inhibitory effects of the natural products indole-3-carbinol and sinigrin during initiation and promotion phases of 4-nitroquinoline-1oxide induced rat tongue carcinogenesis. Jpn J Cancer Res 83: 835-842, 1992.

14. Tanaka T, Kojima T, Hara A, Sawada H and Mori H: Chemoprevention of oral carcinogenesis by DL-a-difluoromethylornithine, an ornithine decarboxylase inhibitor: dosedependent reduction in 4-nitroquinoline-1-oxide-induced tongue neoplasms in rats. Cancer Res 53: 772-776, 1993.

15. Tanaka T, Kojima T, Kawamori T, Wang A, Suzui M, Okamoto K, et al: Inhibition of 4-nitroquinoline-1-oxide-induced rat tongue carcinogenesis by the naturally occurring plant phenolics caffeic, ellagic, chlorogenic and ferulic acids. Carcinogenesis 14: 1321-1325, 1993.
16. Tanaka T, Makita H, Ohnishi M, Hirose Y, Wang A, Mori H, et al: Chemoprevention of 4-nitroquinoline-1-oxide-induced oral carcinogenesis by dietary curcumin and hesperidin: comparison with the protective effect of b-carotene. Cancer Res 54: 4653-4659, 1994.

17. Tanaka T, Kawamori T, Ohnishi M, Okamoto K, Mori H and Hara A: Chemoprevention of 4-nitroquinoline-1-oxide-induced oral carcinogenesis by dietary protocatechuic acid during initiation and postinitiation phases. Cancer Res 54: 2359-2365, 1994.

18. Tanaka T, Makita H, Ohnishi M, Mori H, Satoh K and Hara A: Chemoprevention of rat oral carcinogenesis by naturally occurring xanthophylls, astaxanthin and canthaxanthin. Cancer Res 55: 4059-4064, 1995.

19. Tanaka T, Makita H, Ohnishi M, Mori H, Satoh K and Hara A: Inhibition of oral carcinogenesis by the arotinoid mofarotene (Ro 40-8757) in male F344 rats. Carcinogenesis 16: 1903-1907, 1995.

20. Makita H, Tanaka T, Ohnishi M, Tamai Y, Torihara M, Yamahara $\mathrm{J}$, et al: Inhibition of 4-nitroquinoline-1-oxideinduced rat oral carcinogenesis by dietary exposure of a new retinoidal butenolide, KYN-54, during the initiation and postinitiation phases. Carcinogenesis 16: 2171-2176, 1995.

21. Kandarkar SV and Sawant SS: The effect of vitamin C on the hamster cheek pouch treated with the water soluble carcinogen 4-nitroquinoline-1-oxide (4NQO). Eur J Cancer B Oral Oncol 32B: 230-237, 1996.

22. Tanaka T, Makita H, Kawabata K, Mori H and El-Bayoumy K: 1,4-Phenylenebis(methylene)selenocyanate exerts exceptional chemopreventive activity in rat tongue carcinogenesis. Cancer Res 57: 3644-3648, 1997

23. Tanaka T, Makita H, Ohnishi M, Mori H, Satoh K, Hara A, et al: Chemoprevention of 4-nitroquinoline-1-oxide-induced oral carcinogenesis in rats by flavonoids diosmin and hesperidin, each alone and in combination. Cancer Res 57: 246-252, 1997.

24. Mori H, Kawabata K, Yoshimi N, Tanaka T, Murakami T, Okada T, et al: Chemopreventive effects of ferulic acid on oral and rice germ on large bowel carcinogenesis. Anticancer Res 19: 3775-3778, 1999.

25. Kawabata K, Tanaka T, Honjo S, Kakumoto M, Hara A, Makita H, et al: Chemopreventive effect of dietary flavonoid morin on chemically induced rat tongue carcinogenesis. Int J Cancer 83: 381-386, 1999.

26. Balasenthil S, Ramachandran CR and Nagini S: Prevention of 4-nitroquinoline-1-oxide-induced rat tongue carcinogenesis by garlic. Fitoterapia 72: 524-531, 2001.

27. Yanaida Y, Kohno H, Yoshida K, Hirose Y, Yamada Y, Mori H, et al: Dietary silymarin suppresses 4-nitroquinoline-1-oxideinduced tongue carcinogenesis in male F344 rats. Carcinogenesis 23: 787-794, 2002.

28. Tanaka T, Kohno H, Sakata K, Yamada Y, Hirose Y, Sugie S, et al: Modifying effects of dietary capsaicin and rotenone on 4nitroquinoline-1-oxide-induced rat tongue carcinogenesis. Carcinogenesis 23: 1361-1367, 2002.

29. Yoshida K, Hirose Y, Tanaka T, Yamada Y, Kuno T, Kohno H, et al: Inhibitory effects of troglitazone, a peroxisome proliferatoractivated receptor gamma ligand, in rat tongue carcinogenesis initiated with 4-nitroquinoline-1-oxide. Cancer Sci 94: 365-371, 2003.

30. Srinivasan P, Sabitha KE and Shyamaladevi CS: Therapeutic efficacy of green tea polyphenols on cellular thiols in 4nitroquinoline-1-oxide-induced oral carcinogenesis. Chem Biol Interact 149: 81-87, 2004.

31. Yamamoto K, Kitayama W, Denda A, Morisaki A, Kuniyasu H, Inoue M, et al: Suppressive effects of a selective cyclooxygenase-2 inhibitor, etodolac, on 4-nitroquinoline-1-oxide-induced rat tongue carcinogenesis. Exp Toxicol Pathol 56: 145-151, 2004.

32. Kuno T, Hirose Y, Hata K, Kato K, Qiang SH, Kitaori N, Hara A, Iwasaki T, Yoshimura T, Wada K, Kobayashi H and Mori H: Preventive effect of fermented brown rice and rice bran on $\mathrm{N}$ nitrosomethylbenzylamine-induced esophageal tumorigenesis in rats. Int J Oncol 25: 1809-1815, 2004.

33. Kuno T, Hirose Y, Yamada Y, Hata K, Qiang SH, Asano N, Oyama T, Zhi H, Iwasaki T, Kobayashi H and Mori H: Chemoprevention of mouse urinary bladder carcinogenesis by fermented brown rice and rice bran. Oncol Rep 15: 533-538, 2006.

34. Katayama M, Sugie S, Yoshimi N, Yamada Y, Sakata K, Qiao Z, Iwasaki T, Kobayashi $\mathrm{H}$ and Mori $\mathrm{H}$ : Preventive effect of fermented brown rice and rice bran on diethylnitrosoamine and phenobarbital-induced hepatocarcinogenesis in male F344 rats. Oncol Rep 10: 875-880, 2003. 
35. Katayama M, Yoshimi N, Yamada Y, Sakata K, Kuno T, Yoshida K, Qiao Z, Vihn PQ, Iwasaki T, Kobayashi H and Mori H: Preventive effect of fermented brown rice and rice bran against colon carcinogenesis in male F344 rats. Oncol Rep 9: 817-822, 2002.

36. Kawabata K, Yamamoto T, Hara A, Shimizu M, Yamada Y, Matsunaga K, Tanaka T and Mori H: Modifying effects of ferulic acid on azoxymethane-induced colon carcinogenesis in F344 rats. Cancer Lett 157: 15-21, 2000.

37. Kramer IR, Lucas RB, Pindborg JJ and Sobin LH: Definition of leukoplakia and related lesions: an aid to studies on oral precancer. Oral Surg Oral Med Oral Pathol Oral Radiol Endod 46: 518-539, 1978.

38. Mori H, Sugie S, Yoshimi N, Hara A and Tanaka T: Control of cell proliferation in cancer prevention. Mutat Res 428: 291-298, 1999.

39. Tanaka T: Chemoprevention of 4-nitroquinoline 1-oxide-induced oral carcinogenesis by citrus auraptene in rats. Carcinogenesis 19: 425-431, 1998.

40. Chia-Hung L and Cheng-Chun C: Suppression on the mutagenicity of 4-nitroquinoline-N-oxide by the methanol extracts of soybean koji prepared with various filamentous fungi. Int J Food Microbiol 110: 19-23, 2006.

41. Esaki H, Kawakishi S, Morimitsu Y and Osawa T: New potent antioxidative o-dihydroxyisoflavones in fermented Japanese soybean products. Biosci Biotechnol Biochem 63: 1637-1639, 1999.
42. Hirota A, Taki S, Kawaii S, Yano M and Abe N: 1,1-Diphenyl2-picrylhydrazyl radical-scavenging compounds from soybean miso and antiproliferative activity of isoflavones from soybean miso toward the cancer cell lines. Biosci Biotechnol Biochem 64: 1038-1040, 2000.

43. Chen YC, Inaba M, Abe N and Hirota A: Antimutagenic activity of 8-hydroxyisoflavones and 6-hydroxydaidzein from soybean miso. Biosci Biotechnol Biochem 67: 903-906, 2003

44. Benjamin H, Storkson J, Nagahara A and Pariza MW: Inhibition of benzo(a)pyrene-induced mouse forestomach neoplasia by dietary soy sauce. Cancer Res 51: 2940-2942, 1991.

45. Fukutake M, Takahashi M, Ishida K, Kawamura H, Sugimura T and Wakabayashi K: Quantification of genistein and genistin in soybeans and soybean products. Food Chem Toxicol 34: 457-461, 1996.

46. Ohta T, Nakatsugi S, Watanabe K, Kawamori T, Ishikawa F, Morotomi M, Sugie S, Toda T, Sugimura T and Wakabayashi K: Inhibitory effects of Bifidobacterium-fermented soy milk on 2amino-1-methyl-6-phenylimidazo[4,5-b] pyridine-induced rat mammary carcinogenesis, with a partial contribution of its component isoflavones. Carcinogenesis 21: 937-941, 2000.

47. Shimoji Y, Tamura Y, Nakamura Y, Nanda K, Nishidai S, Nishikawa $\mathrm{Y}$, Ishihara N, Uenakai $\mathrm{K}$ and Ohigashi $\mathrm{H}$ : Isolation and identification of DPPH radical scavenging compounds in Kurosu (Japanese unpolished rice vinegar). J Agric Food Chem 50: 6501-6503, 2002. 